\title{
Urinary androgen concentrations and social status in two species of free ranging zebra (Equus burchelli and E. grevyi)*
}

\author{
M. Chaudhurit§ and J. R. Ginsberg $\ddagger$ \\ $\lceil$ New York Zoological Society, Bronx, NY 10460, USA; and $\ddagger$ Department of Biology, \\ Princeton University, Princeton NJ 08544, USA
}

\begin{abstract}
Summary. In both species of zebra, breeding males had higher urinary androgen concentrations (ng androgens/mg $\mathrm{Cr}$ ) than did non-breeding bachelor males $(30.0 \pm 5 \cdot 0$ $(\mathrm{N}=9)$ versus $11 \cdot 4 \pm 2 \cdot 8,(\mathrm{~N}=7)$ in the plains zebra; $19.0 \pm 2 \cdot 2(\mathrm{~N}=17)$ versus $10 \cdot 7 \pm 1 \cdot 2(\mathrm{~N}=14)$ in the Grevy's zebra). In the more stable family structure of the plains zebra (single male non-territorial groups) variations in androgen concentrations could not be ascribed to any measured variable. In the Grevy's zebra, androgen values were significantly lower in samples taken from territorial (breeding) males which had temporarily abandoned their territories $(N=4)$ and the urinary androgen concentration for a male on his territory was negatively correlated with the time since females last visited the territory.
\end{abstract}

Keywords: zebra; testosterone; androgens; territoriality; social behaviour; dominance

\section{Introduction}

Members of the family Equidae show two patterns of social organization (Klingel, 1975). In the first type, typified by the plains zebra, Equus burchelli, a single breeding male is found in constant association with a fixed group of 1-6 unrelated females and their offspring. These groups, or harems, show little sight fidelity. Mating activity shows seasonal peaks coincident with periods of food abundance, but mating may occur at any time throughout the year (Klingel, 1969). Bachelor males remain in fixed membership groups separate from harems and have never been observed mating with adult females (Klingel, 1969). In the second type of social organization, represented in this study by the Grevy's zebra, Equus grevyi, there are no permanent bonds between any two individuals nor is there any seasonality in breeding (Klingel, 1974; Ginsberg, 1987, 1989). Breeding males defend territories in which they retain exclusive access to oestrous females when present. K lingel (1974) never observed bachelor males mating. Of 94 copulations observed by Ginsberg (1987), $87(93 \%)$ were made by territorial males while on their territories.

For this study, data were collected from a free ranging population of zebras in their natural habitat to examine whether there is a potential hormonal basis for both intra- and inter-specific differences in male behaviour. Data from other studies suggest that it is likely that there is an endocrinological basis to the different behaviours observed in the various groups of males. In the congeneric domestic horse, E. caballus, the secretion of luteinizing hormone and testosterone show seasonal variations (Berndtson et al., 1974, 1983) as do seminal and behavioural characteristics

\footnotetext{
*Reprint requests to Dr J. R. Ginsberg.

\$Present address: Memorial Sloane Kettering Cancer Institute, Box 40, 1275 York Avenue, New York, NY 10021, USA.

'Present address: Department of Zoology, University of Oxford, South Parks Rd, Oxford OXI 3PS, UK.
} 
(Pickett et al., 1970; Thompson et al., 1977) suggesting an endocrine mechanism. The seasonality of these changes coincides with the breeding cycles of females.

\section{Materials and Methods}

Study area. Data were collected in the Buffalo Springs Reserve, in the region around the town of Archer's Post, Kenya $\left(37^{\circ} 30^{\prime} \mathrm{E}, 0^{\circ} 40^{\prime} \mathrm{N}\right)$. The study area, while climatologically homogeneous (dry and hot), is vegetationally diverse. This diversity is apparent even on a small scale (Barkham \& Rainy, 1976). Average rainfall for the Archer's Post Station is $365 \mathrm{~mm}$ (Government of Kenya, 1984) with the maximum rainfall occurring in two seasons, March/April and October/November.

Definition of behavioural status of males. Urine samples were collected from known individuals identified by their unique stripe patterns (Peterson, 1972; Klingel, 1974). In both species, males were placed into one of two categories, breeding or bachelor, according to differences in behaviour. In the plains zebra, an adult male was considered to be a breeding, or harem, male if he was seen in association with a particular group of females and juveniles on at least $90 \%$ of all observations. In contrast, bachelor males were nearly always observed in fixed membership groups with other bachelor males.

In the Grevy's zebra, neither bachelor males nor territorial males were seen in consistent association with other individuals. Territorial males make frequent forays off their territories and were usually seen in association with bachelor males at these times (Ginsberg, 1987). While on territory, the breeding male exhibited typical patterns of behaviour (calling, marking), a distinctive posture, and dominance over all other individuals (Klingel, 1974).

Behavioural measurements were taken on 1084 individual Grevy's zebra identified by their stripe patterns. Zebra stripes are individually distinct (Klingel, 1974) and identifications were made with an accuracy of at least $98 \%$ (Ginsberg, 1987). Information was collected daily on the distribution and identity of the zebra in the study area. Point-sample data, collected for 9795 sightings ( 5061 males; 4734 females) during the entire study, provide records of associations of individual zebra. Of course, not all zebra were identified on all days nor, given the scope of the study, were animals observed continuously.

Urine collection. In both species, urinary testosterone concentrations of potentially breeding males (territorial for the Grevy's zebra, and harem breeding for the plains zebra) were compared to those of non-breeding males. Within the sub-sample of breeding males, variations in androgen concentrations were examined to determine the effect of time of day, season, and association with both bachelor males and females. Urine was collected from zebras in April, May and June of 1985. Males were observed urinating and the urine was aspirated from the ground using a sterile 10-ml syringe. Samples were collected within $5 \mathrm{~min}$ of urination and were stored in glass jars, packed on ice and frozen on return to camp at $-5 \mathrm{C}$. Specimens were transferred to Nairobi on a monthly basis and stored at $-20 \mathrm{C}$. At the time of collection, the following data were recorded: time of day; individual identification; group composition (no. of males, no. of females, presence/absence of oestrous females); breeding male or bachelor male; if territorial, on or off territory. In addition, for territorial male Grevy's zebra, the time since last association with either bachelor males or females was calculated from data collected on daily surveys of all individuals within the study area.

During the period in which urine samples were collected, none of the plains zebra harem males were observed in association with oestrous females. Because the duration of oestrus in the plains zebra is brief ( $\simeq 1$ day, J. R. Ginsberg. unpublished data), the possibility that a harem male was in association with an oestrous female the day preceding collection of a sample cannot be eliminated.

Androgen assay. All androgen values are expressed relative to urinary creatinine $(\mathrm{Cr})$ concentrations to allow for correction of variation in urinary water content. The procedure of Taussky (1954) was used to measure $\mathrm{Cr}$ and the sensitivity of the assay was $0 \cdot 1 \mathrm{mg} / \mathrm{ml}$ urine.

The urine samples were subjected to acid hydrolysis. An aliquant of each urine sample $(0 \cdot 4 \mathrm{ml})$ was diluted $1: 2 \cdot 5$ with water and $0.2 \mathrm{ml}\left[2 \mathrm{~N}-\mathrm{HCl} ; 1500 \mathrm{c} . \mathrm{p} . \mathrm{m}\right.$. [ $\left.{ }^{3} \mathrm{H}\right]$ testosterone $/ 0.1 \mathrm{ml}$ were added for recovery calculations. This mixture was incubated in a boiling water bath for $15 \mathrm{~min}$. After neutralization with sodium hydroxide, an aliquant of this hydrolysed urine $(0.05 \mathrm{ml})$ was extracted twice with $5 \mathrm{ml}$ freshly opened diethyl ether. The extract was dried under a stream of nitrogen and then reconstituted in $1.0 \mathrm{ml}$ assay buffer $(0 \cdot 1 \mathrm{M}$-phosphate, $\mathrm{pH} 7 \cdot 0$, containing $0.9 \%$ ( $w / v)$ sodium chloride, $0.01 \%$ sodium azide and $1 \%$ gelatin). A $0.5 \mathrm{ml}$ sample was counted for recovery while $0.05 \mathrm{ml}$ was assayed for androgens by radioimmunoassay as described by Janne et al. (1974). Two samples were run from each sample and no inter-assay differences were found. The antiserum was raised in rabbits against testosterone17-hemisuccinate-BSA. The major cross-reactions were $18 \cdot 2 \%$ with $5 \alpha$-dihydrotestosterone and $12.9 \%$ with $5 \beta$ dihydrotestosterone. The assay tubes containing the sample, antibody, and $\left[1,2,6,7,16,17-{ }^{3} \mathrm{H}\right]$ testosterone (sp. act. $135 \mathrm{Ci} / \mathrm{mmol}$ : New England Nuclear, Boston, MA, USA) were incubated for $2 \mathrm{~h}$ at $4 \mathrm{C}$. The separation of antibodybound and free steroid was achieved by addition of $0.5 \mathrm{ml}$ charcoal-dextran $(0.5 \%$ charcoal Norit $\mathrm{A}, 0.05 \%$ dextran in the assay buffer) during a 15 -min incubation at 4 C. After centrifugation for 15 min, the supernatant was decanted and mixed with scintillation cocktail and counted for $5 \mathrm{~min}$. The standard curve ranged from 3 to $1000 \mathrm{pg} /$ tube and the lowest detectable sample measured was $3 \mathrm{ng} / \mathrm{ml}$ urine. Serial dilutions of hydrolysed zebra urine showed parallelism with the standard curve. All the samples were run in a single assay and the mean \pm s.e.m. recovery of titrated testosterone added to the hydrolysed urine was $72.9 \pm 1.8 \%, n=53$ ). Various known amounts of unlabelled 
testosterone were also added to a pool of zebra urine before hydrolysis. The mean \pm s.e.m. recovery was $77 \cdot 8 \pm 8 \cdot 9 \%$ $(n=8)$.

Body size. Body size was estimated using photometric analysis for the Grevy's zebra. Complete details of the method are given by Ginsberg (1987). Linear girth, the distance from the withers to the belly, was estimated and used as the measure of body size. For any particular individual, estimates of linear girth had an error of $\simeq 8 \%$. Given that arid-zone adapted equids can vary in weight up to $20 \%$ due to dehydration (Maloiy, 1970), linear girth measurements appear to provide an accurate measure of relative size.

Statistical analysis. Statistical analyses were performed on an Apple Macintosh S.E. running Statview software (Abacus Concepts, 1986). As data were not found to deviate from a normal distribution, parametric statistics were used throughout. Results are expressed as the mean of all values \pm the standard error of the mean (s.e.m.).

\section{Results}

\section{Plains zebra}

Harem (breeding) males had significantly higher androgen concentrations than did bachelor males (Fig. 1: $30 \cdot 0 \pm 5.9 \mathrm{ng} / \mathrm{mg} \mathrm{Cr}, \mathrm{N}=9$, versus $11.4 \pm 2.8 \mathrm{ng} / \mathrm{mg} \mathrm{Cr}, \mathrm{N}=7$; d.f. $=13, t=3 \cdot 23$, $P<0.01)$. Among harem males, neither the time of day at which samples were collected $\left(r^{2}=0.01\right.$, $P>0.50$ nor the number of females in a male's harem $\left(r^{2}=0.16, P>0.30\right)$ had any significant effect on androgen concentrations. No data on body size were available for plains zebra.

\section{Grevy's zebra}

Territorial males had higher concentrations of androgens than did bachelor males (Fig. 1: $19 \cdot 0 \pm 2 \cdot 2 \mathrm{ng} / \mathrm{mg} \mathrm{Cr}, \mathrm{N}=17$, versus $10 \cdot 7 \pm 1 \cdot 2 \mathrm{ng} / \mathrm{mg} \mathrm{Cr}, \mathrm{N}=14 ; \mathrm{d} . \mathrm{f} .=29, t=3 \cdot 13, P<0 \cdot 01)$. Samples were collected from 4 territorial males who were on forays off their territories. These results show that when a territorial male is off his territory he is likely to have reduced androgen values compared to concentrations in the same male when he is on territory (Fig. 1: paired Student's $t$ test, d.f. $=3, t=2.49, P<0.05$ ). There was no significant difference in androgen concentrations between off-territory males and bachelor males (d.f. $=16, t=0.93, P>0 \cdot 30$ ).

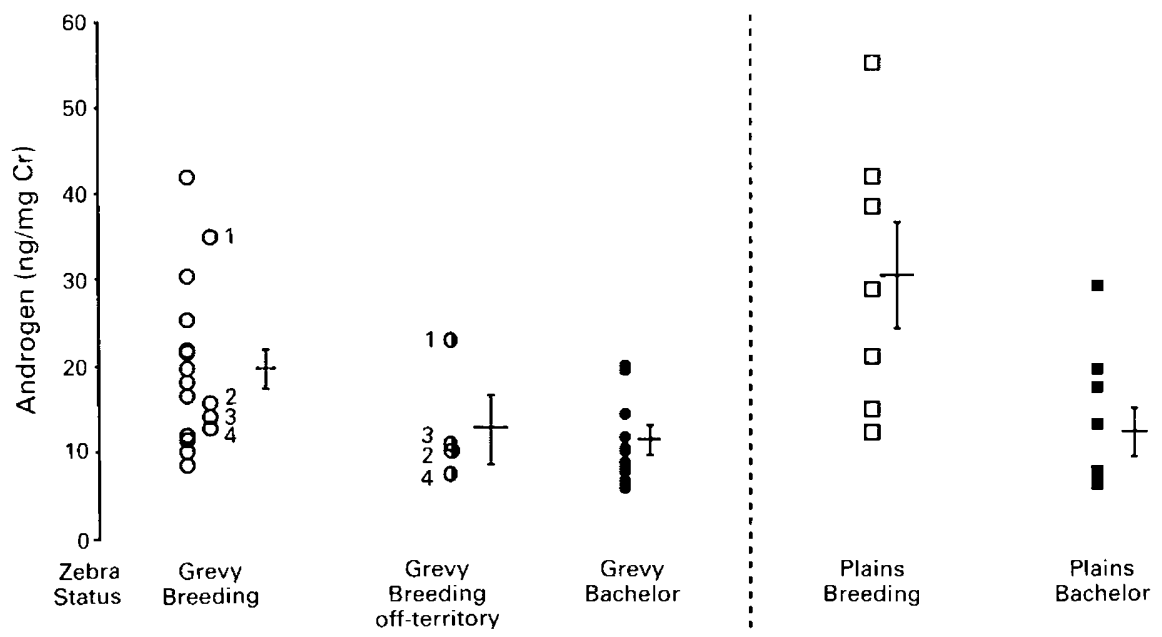

Fig. 1. Urinary androgen concentrations (mean \pm s.e.m.) for two species of zebras. For Grevy's zebra, samples were collected from 4 breeding individuals both on and off their territories. In the first column (open circles), these samples are numbered and are slightly off-set to the right. Samples in column two for corresponding males are similarly numbered. 
In samples taken from territorial males, neither the presence of females $(N=4)$ at the time of sampling (d.f. $=15, t=0.77, P>0.40$ ), nor the presence of bachelor males $(\mathrm{N}=3)$ at the time of sampling (d.f. $=15, t=0.64, P>0.50$ ), or the time of day at which samples were collected $\left(r^{2}=0 \cdot 14, P>0 \cdot 10\right)$ affected androgen concentrations.

There was no correlation of urinary androgen concentrations with the time since last association with bachelor males (d.f. $=16, P>0 \cdot 10$ ) but there was a negative correlation between urinary androgen concentrations and the time since a territorial male was last seen in association with at least one female (Fig. $2: y=-0.43 x+22 \cdot 2, r^{2}=0.26, P<0.05$ ).

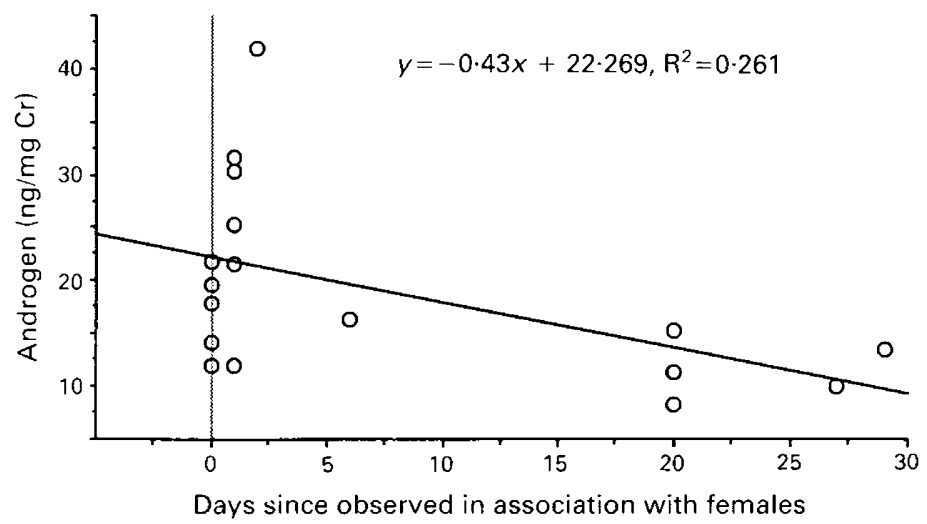

Fig. 2. The effect of absence of females on testosterone concentration in territorial Grevy's zebra males.

Among bachelor males and territorial males, body size had no effect on urinary androgen concentrations. When males of both types were simultaneously included in the analysis, there was a strong correlation between body size and urinary androgen concentrations (d.f. $=27$, $y=0.951 x-48.5, r^{2}=0.25, P<0.01$ ).

\section{Discussion}

The results of this study indicate that, despite marked differences in social organization, breeding males of both the Grevy's and plains zebra exhibit similar endocrine changes. In both species, males that have access to females (i.e. potentially breeding males) excrete more androgens than do nonbreeding males. Hence, there is an endocrinological correlation with social dominance, as measured by access to sexually receptive females, which appears to be consistent across breeding systems.

The use of a urinary assay for androgens had several advantages. The method allowed samples to be collected, without immobilizing animals, from a large number of individuals in free-ranging wild populations of two sympatric species of zebra. One of the species, the Grevy's zebra, is classified as endangered (Thornback, 1977). As immobilization of wild equids is often difficult (King \& Klingel, 1965), collection of samples on the scale required would have been impossible. Furthermore, the fluctuations observed in plasma androgen measurements (Katangole et al., 1971; Bartke et al., 1973) are minimized using urinary samples since they presumably reflect androgen secretion over a period of several hours. It was assumed that most of the androgens were of testicular origin as in other species the contribution of the adrenals is minimal.

The correlation between dominance and androgen concentrations has been observed in a wide variety of other ungulate families including bovids (impala, Aepyceros melampus: Bramley \& 
Neaves, 1972), cervids (red deer, Cervus elephus: Lincoln et al., 1972; white-tailed deer, Odocoileus virginianus: Miller et al., 1987) and elephants (African elephant, Loxodonta africana: Poole et al., 1984). In experiments with antelopes, territorial males had higher plasma testosterone values than did bachelor males in response to gonadotrophin-releasing hormone (Illius et al., 1983).

In the Grevy's zebra, the results suggested further endocrine-behavioural interrelationships. That the concentration of androgen appeared to decline when females had not recently been present suggests that social stimuli may be a factor influencing androgen secretion. When females have not visited a territory for some time, males will temporarily abandon their territories (Ginsberg, 1987), and so the fact that males which have temporarily abandoned their territories have lower concentrations of androgens is not surprising.

That association with other males does not affect androgen concentrations may be due to small sample sizes. A territorial male may spend up to several weeks on territory without being in association with either males or females (Ginsberg, 1987). Hence, another way to evaluate the effect of conspecifics on androgen concentrations is to examine the relationship between urinary androgen concentrations in samples taken from territorial males as a function of the time since their last association with conspecifics.

While these data demonstrate that there is an endocrinological basis to dominance in zebra, the direction of causality cannot be determined from these observations. In a variety of other species, sexual activity (rabbit: Ågmo, 1976; ram: Sanford et al., 1974; Gonzalez et al., 1988; boar: Liptrap \& Raeside, 1978; bull: Katangole et al., 1971; mouse: Coquelin \& Bronson, 1980; rat: Kamal \& Frankel, 1978; rhesus monkey: Herndon et al., 1981) or merely exposure to females (ram: Gonzalez et al., 1988) or their scent (hamster: Macrides et al., 1974) led to elevated concentrations of serum testosterone. In boars, aggressive encounters also led to increased concentrations of testosterone in the blood (Liptrap \& Raeside, 1978); however, in the lesser mouse lemur, only dominant males showed higher levels of testosterone after aggressive encounters (Peret, 1985). In other studies sexual activity (bull: Price et al., 1986; ram: Moore et al., 1978) and aggressive encounters (bull: Price et al., 1986) had little or no effect on serum testosterone concentrations.

It remains to be determined whether, in zebra, increasing concentrations of androgens cause an animal to be dominant, or whether high androgen concentrations are characteristic of dominant males. It is tempting to suggest that proximity to females raises androgen concentrations which, in turn, increases aggression enabling the dominant male to defend his mate. However, further research is required to confirm this hypothesis.

Physical factors could also have an effect on androgen concentrations. As all samples were collected at the same time of the year, differences observed cannot be ascribed to seasonality. In red deer stags, testosterone was correlated with aggressive behaviour, while dominance position was affected by other variables including weight, antler size, age and experience in addition to testosterone concentrations (Lincoln et al., 1972). In this study, within a reproductive class (territorial or bachelor), there was no correlation between size and androgen concentrations. When reproductive classes were pooled, there was a significant effect of body size on androgen level. However, as territorial males are larger than bachelor males (Ginsberg, 1989), the size and reproductive class are highly auto-correlated. Furthermore, among territorial males, male reproductive success is not correlated to body size (Ginsberg, 1989). Given the intra-individual variation in urinary androgen concentrations among males on and off their territories, it seems unlikely that body size has an independent significant effect.

The results of this study demonstrate that, in zebras, androgen values and the reproductive status of individual males are inter-related. In the more stable family structure of the plains zebra, in which association of a breeding male and his females is essentially constant, little can be concluded other than that breeding males have higher androgen concentrations than do bachelor males. The fluid social organization of the Grevy's zebra allows a more detailed analysis of how different social variables affect androgen values. For this species we show that the hormone concentrations changed with the breeding status, and social situation, of the male being studied. 
We thank the Population Council for assistance with the hormone assays; Dr R. B. Thau for critical advice on writing the manuscript; Ms Emilee Carrasco for technical assistance; S. K. and W. R. Ginsberg for help with the collection and transport of specimens; and the Office of the President of the Republic of Kenya, the Wildlife Conservation and Management Department, Kenya, the Department of Zoology, University of Nairobi, and Princeton University for sponsoring this research. M.C. was supported by grants from the Marilyn M. Simpson Charitable Trust and the Bay Foundation. Field research was funded by the National Geographic Society (grants 3022-85 and 2638-83), and the New York Zoological Society.

\section{References}

Abacus Concepts (1986) Statview User's Manual. BrainPower Inc., Calabasas.

Ågmo, A. (1976) Serum luteinizing hormone and testosterone after sexual stimulation in male rats. Acta physiol. scand. 96, 140-142.

Barkham, J.P. \& Rainy, M.E. (1976) The vegetation of the Samburu-Isiolo Game Reserve. E. Afr. Wildl. J. 14, 297-329.

Bartke, A., Steele, R.E., Musto, N. \& Caldwell, B.V. ( 1973) Fluctuations in plasma testosterone levels in adult male rats and mice. Endocrinology 92, 1223-1228.

Berndtson, W.E., Pickett, B.W. \& Nett, T.M. (1974) Reproductive physiology of the stallion. IV. Seasonal changes in the testosterone concentration of peripheral plasma. J. Reprod. Fert. 39, 115-118.

Berndtson, W.E., Squires, E.L. \& Thompson, D.L. (1983) Spermatogenesis, testicular composition and the concentration of testosterone in the equine testis as influenced by season. Theriogenology 20, 449-457.

Bramley, P.S. \& Neaves, W.B. (1972) The relationship between social status and reproductive activity in male impala (Aepyceros melampus). J. Reprod. Fert. 31, 77-81.

Coquelin, A. \& Bronson, F.H. (1980) Secretion of luteinizing hormone in male mice: factors that influence release during sexual encounters. Endocrinology 106, 1224-1229

Ginsberg, J.R. (1987) Social organization and mating strategies of an arid adapted equid: the Grevy's zebra. Ph.D. dissertation, Princeton University. 267 pp.

Ginsberg, J.R. (1989) The ecology of female behaviour and male mating success in the Grevy's zebra (Equus grevyi). Symp. zool. Soc. Lond. 61, 89-110.

Gonzalez, R., Poindron, P. \& Signoret, J.P. (1988) Temporal variation in $\mathrm{LH}$ and testosterone responses of rams after the introduction of oestrous females during the breeding season. J. Reprod. Fert. 83, 201-208.

Government of Kenya (1984) Summary Rainfall in Kenya. Kenya Meterological Department, Nairobi.

Herndon, J.G., Perachio, A.A., Turner, J.J. \& Collins, D.C. (1981) Fluctuations in testosterone levels of male rhesus monkeys during copulatory activity. Physiol. Behav. 26, 525-528.

Illius, A.W., Haynes, N.B., Lamming, G.E., Howles, C.M. \& Fairall, N. (1983) Evaluation of LH-RH stimulation of testosterone as an index of reproductive status in rams and its application in wild antelope. J. Reprod. Fert. 68, 105-112.
Janne, O., Apter, D. \& Vihko, R. (1974) Assay of testosterone, progesterone, and $17 \alpha$-hydroxyprogesterone in human plasma by radioimmunoassay after separation on hydroxyalkoxypropyl sephadex. J. Steroid Biochem. 5, 155-162.

Kamal, F. \& Frankel, A. (1978) Hormone release during mating in the male rat: time course, relation to sexual behaviour, and interaction with handling procedures. Endocrinology' 103, 2172-2179.

Katangole, C.B., Naftolin, F. \& Short, R.V. (1971) Relationship between blood levels of luteinizing hormone and testosterone in bulls and the effects of sexual stimulation. J. Endocr. 50, 457-466.

King, J.M. \& Klingel, H. (1965) The use of the oripavine derivative M.99 for the restraint of equine animals. and its antagonism with the related compound M.285. Res. vet. Sci. 6, 447-455.

Klingel, H. (1969) Reproduction in the plains zebra (Equus burchelli boehmi), behaviour and ecological factors. J. Reprod. Fert.. Suppl. 6, 339-345.

Klingel, H. (1974) Social organization and behaviour of the Grevy's zebra. Z. Tierpsychol. 36, 36-70.

Klingel, H. (1975) Social organization and reproduction in equids. J. Reprod. Fert., Suppl. 23, 7-11.

Lincoln, G.A., Guinness, F. \& Short, R.V. (1972) The way in which testosterone controls the social and sexual behaviour of the red deer stag (Cervus elaphus). Horm. \& Behav. 3, 375-396.

Liptrap, R.M. \& Raeside, J.I. (1978) A relationship between plasma concentrations of testosterone and corticosteroids during sexual and aggressive behaviour in the boar. $J$. Endocr. 76, 75-85.

Macrides, F., Bartke, A., Fernandez, F. \& S'Agelo, W. (1974) Effects of exposure to vaginal odor and receptive females on plasma testosterone in the male hamster. Neuroendocrinology' 15, 355-364.

Maloiy, G.M.O. (1970) Water economy of the Somali donkey. Am. J. Physiol. 219, 1522-1527.

Miller, K.V., Marchington, R.L., Forand, K.J. \& Johansen, K.L. (1987) Dominance, testosterone levels and scraping activity in a captive herd of white-tailed deer. J. Mammal. 68, 812-817.

Moore, R.W., Whyman, D. \& Wilson, P.R. (1978) Effects of sexual stimulation on plasma levels of LH and testosterone in rams from high- and low-fertility flocks. J. Reprod. Fert. 53, 67-70.

Peret, M. (1985) Influence of social factors on seasonal variation in plasma testosterone levels of Microcebus murinus. Z. Tierpsychol. 69, 265-280. 
Peterson, J.C.B. (1972) An identification system for zebra (Equus burchelli, Gray). E. Afr. Wildl. J. 10, 59-63.

Pickett, B.W., Faulkner, L.C. \& Sutherland, T.M. (1970) Effect of month and stallion on seminal characteristics and sexual behavior. J. Anim. Sci. 31, 713-728.

Poole, J.H., Kasman, L.H., Ramsay, E.C. \& Lasley, B.L. (1984) Musth and urinary testosterone concentrations in the African elephant (Loxodonta africana). $J$. Reprod. Fert. 70, 255-260.

Price, E.O., Katz, L., Moberg, G.P. \& Wallach, S.J.R. (1986) Inability to predict sexual and aggressive behaviors by plasma concentrations of testosterone and luteinizing hormone in hereford bulls. J. Anim. Sci. 62, 613-617.
Sanford, L.M., Palmer, W.M. \& Howland, B.E. (1974) Influence of sexual activity on serum levels of LH and testosterone in the ram. Can.J. Anim. Sci.54,579-585.

Taussky, H.H. (1954) A microcolorimetric determination of creatinine in urine by the Jaffe reaction. $J$. biol. Chem. 208, 53-61.

Thompson, D.L., Jr, Pickett, B.W., Berndston, W.E., Voss, J.L. \& Nett, T.M. (1977) Reproductive physiology of the stallion. VIII. Artificial photoperiod, collection interval and seminal characteristics, sexual behavior and concentration of $\mathrm{LH}$ and testosterone in serum. J. Anim. Sci. 44, 656-664.

Thornback, J. (Ed.) (1977) Red Data Book, Mammals. IUCN, Morges Switzerland.

Received 16 March 1989 